RTIGOS 


\title{
Entre camisas e fantasias: a arte de fazer o chão afro-brasileiro do Salgueiro'
}

\author{
Between shirts and costumes: the art of making the \\ African-Brazilian ground of Salgueiro
}

\section{Vítor Gonçalves Pimenta}

Brasil. Universidade Federal Fluminense. Doutorando em Antropologia pelo Programa de Pós-Graduação em Antropologia da Universidade Federal Fluminense. Auxiliar de pesquisa no Laboratório de Etnografia e Estudos em Comunicação, Cultura e Cognição. ID ORCID: https://orcid.org/0000-0002-4288-0021.E-mail:torpimenta@gmail.com.

\section{Resumo}

Neste trabalho, busco pensar estética e politicamente a performance do chão afrobrasileiro nos ensaios e desfiles da escola de samba Acadêmicos do Salgueiro na cidade do Rio de Janeiro, a partir da cultura material, principalmente das camisas e fantasias dos componentes. $\mathrm{O}$ chão da escola corresponde à comunidade do Salgueiro, ou seja, um grande grupo de corpos, que se subdividem nas diversas alas que compõem a agremiação da escola e são responsáveis por seu assentamento. A comunidade é formada pelos três casais de mestre-sala e porta-bandeira, pelas alas das baianas, da Velha Guarda, dos(as) passistas, da bateria e dos compositores, além das alas que contam o enredo da escola, dos/as componentes das alegorias, e, ainda, da equipe do carro de som, composta por instrumentistas, intérpretes e diretores de harmonia. Assim, partindo de uma observação participante e dançante e da utilização de entrevista semiestruturada, o objetivo é refletir sobre a comunidade que faz o carnaval na sua dimensão performática, focando sua produção identitária através dos objetos.

Palavras-chave: Camisas, Fantasias, Alegórico, Brincadeira, Salgueiro

Agradeço à Faperj por financiar minha pesquisa de doutorado e seus desdobramentos. Agradeço ao professor Daniel Bitter (UFF) as ideias sobre o tema do artigo. Agradeço aos/às componentes do Salgueiro. Sem eles/as este trabalho não seria possível.

Recebido em 13 de junho de 2019. Avaliador A: 26 de julho de 2019. Avaliador B: 04 de agosto de 2019. Aceito em 04 de agosto em 2019. 


\section{Abstract}

This study discusses the aesthetics and politics of the performance of AfricanBrazilian grounds in the rehearsals and parades of "Acadêmicos do Salgueiro", a samba school in Rio de Janeiro. Its ground corresponds to the community, that is, a large group of bodies that is subdivided into the various wings (called "alas") that constitute the samba school, responsible for its settlement. The Salgueiro Samba School consists of "ala das baianas", the old guard ward, the three couples of "mestre-sala and porta-bandeira" (Master of Ceremonies and Flag Bearer), the dancers' ward ("passistas"), the percussion section, the wards that tell the story or explain the thematic presented by the samba school in its parade, as well as its members on allegorical floats. Additionally, the sound car team is formed by musicians, singers and harmony directors. Thus, participant observation (including being part of the dance team) was paired with semi-structured interviews to reflect upon the community that constitutes the "Carnaval" in the Salgueiro samba school by focusing on its identity production through its objects.

Keywords: Shirts, Costumes, Allegorical, Play, Salgueiro

\section{INTRODUÇÃO}

Depois de reverberar algumas questões importantes sobre os corpos brincantes que fazem o carnaval do Grêmio Recreativo Escola de Samba Acadêmicos do Salgueiro no artigo intitulado "Algumas reverberações sobre o chão do Salgueiro" ${ }^{2}$, considero oportuno me debruçar sobre a produção identitária dos/as componentes da comunidade através dos objetos: camisas e fantasias.

No artigo anterior, experimentou-se os ensaios da comunidade, seguindo as palavras de Senghor (1982), quebrando a dicotomia entre teoria e prática e produzindo um espaço de conhecimento, "onde um corpo sente o outro corpo, onde um corpo dança o outro corpo, onde corpos se conectam uns aos outros na experiência dinâmica, vital de conhecer e compreender o mundo a partir de seus corpos dançantes, que brincam de sambar o mundo" (PIMENTA, 2017, p. 20).

Artigo apresentado no XVI Congresso de Antropologia na Colômbia e no V Congresso da Associação Latino-americana de Antropologia 
Aqui, o objetivo é partir de uma percepção sobre o caráter estético e político dos movimentos dos/as componentes, percebidos sob a ótica das relações entre lugar, ritmo e gestualidade, como realizado anteriormente, somando-se uma reflexão sobre a relação de camisas e fantasias e os corpos brincantes, indagando os/as componentes por meio de entrevista semiestruturada. As entrevistas qualitativas seguiram roteiro pré-definido, composto por perguntas abertas, tratando de questões referentes à origem e trajetória social e à ala da comunidade ou comercial - relação com a escola, lembranças de outros carnavais, de assistir ao desfile, os ensaios, o samba enredo, as fantasias, o ensaio técnico, o desfile e o patrimônio.

De uma maneira ampla, compreende-se que esses objetos exercem funções identitárias, manifestando simbolicamente nossas identidades individuais e sociais e, ainda, organizam, individualmente e coletivamente, nosso entendimento sobre nós mesmos (CLIFFORD, 1985; GONÇALVES, 2007). Em outras palavras, "o vestuário desempenha papel considerável e atuante na constituição da experiência particular do eu" (MILLER, 2013, p. 63). Nesse sentido, analisando a cultura material, Miller questiona a concepção que opõe coisas e pessoas. A tentativa é de compreender tanto como as pessoas fazem as coisas quanto como as coisas fazem as pessoas. Por exemplo, as roupas e carros, uma vez feitos, tornam-se parte do que somos, ou seja, "os objetos nos fazem como parte do processo pelo qual os fazemos [...]. Em última análise, não há separação entre sujeitos e objetos [...]. Fazer carros produz uma nova versão de nós mesmos" (MILLER, 2013, p. 92). Para esclarecer a questão, o autor analisa principalmente as contribuições de Hegel na obra Fenomenologia do espírito e Marx na referência Manuscritos econômicos e filosóficos.

Marx começa com uma visão. A natureza em si não pertence a ninguém. Assim, as coisas que criamos a partir dela deveriam beneficiar os que são responsáveis por essa criação. Sim começamos com a objetificação como um processo pelo qual nos criamos. Porém, como argumentou Hegel, uma vez que uma coisa seja externalizada, ela também pode se tornar opressiva, e podemos perder a consciência de que um dia ela foi criação nossa. Marx argumentou que isso acontece no capitalismo, que engana os trabalhadores fazendo-os pensar que o que faz o mundo material não é o trabalho deles, mas os recursos do capital (MILLER, 2013., p. 92-93). 
Na concepção de Marx e dos marxistas, "os objetos são reduzidos às mercadorias fornecidas pelo capitalismo. Os marxistas usam sobretudo termos como fetichismo, reificação e alienação. A essa altura, a palavra objetificação se tornou mais literal - sujeitos tornados em objetos" (MILLER, 2013, p. 93). Miller analisa a visão de Marx e dos marxistas para problematizar a relação entre sujeitos e objetos. Assim, afasta-se da visão marxista e se aproxima do horizonte hegeliano: "De forma clara, os trecos podem se virar contra nós e se tornar opressivos, mas é preferível ver isso como contradição, e não como a única maneira de caracterizar nossa relação com as coisas" (MILLER, 2013, p. 93).

No debate sobre cultura material, Miller apresenta outras perspectivas teóricas em sua obra: "Bruno Latour, por exemplo, parece convencido de que a teoria dialética apenas ressuscita a oposição entre sujeitos e objetos, ao passo que eu acredito que ela consegue transcendê-los" (MILLER, 2013, p. 115). No campo antropológico, Alfred Gell transcendeu "a oposição entre coisas e pessoas dizendo que objetos têm a 'agência' - embora Gell use a palavra para criar uma abordagem da arte. Também exercem influência várias versões da fenomenologia esposada, por exemplo, por antropólogos como Ingold e Tilley" (MILLER, 2013, p. 115).

Ingold (2012) considera que o mundo é composto por coisas e não por objetos.

O objeto coloca-se diante de nós como um fato consumado, oferecendo para nossa inspeção suas superfícies externas e congeladas. Ele é definido por sua própria contrastividade com relação à situação na qual ele se encontra [...]. A coisa, por sua vez, é um "acontecer", ou melhor, um lugar onde vários aconteceres se entrelaçam (INGOLD, 2012, p. 29).

As coisas estão vivas. Elas vazam. Habitar o mundo é um processo de formação contínua. A ênfase na agência material reduz coisas a objetos e retira os processos vitais.

Se as pessoas podem agir sobre os objetos que as circundam, então, argumenta-se, os objetos "agem de volta" e fazem com que elas façam, ou 
permitem que elas alcancem, aquilo que elas de outro modo não conseguiriam [...]. Não obstante, no primeiro movimento teórico que toma as coisas para enfocá-las em sua qualidade de objeto (objectness), elas são retiradas dos fluxos que as trazem à vida (INGOLD, 2012, p. 33).

Ao focar nos processos vitais, o autor aborda os fluxos materiais e não a materialidade enquanto tal. "Como Deleuze e Guattari, temos que seguir esses fluxos, traçando os caminhos através dos quais a forma é gerada, onde quer que eles nos levem.” (INGOLD, 2012, p. 27). O que interessa para o autor é refletir sobre o "material" em movimento. "Pensar a pipa como um objeto é omitir o vento - esquecer que ela é, antes de tudo, uma pipa-no-ar. E, assim parece, o voo da pipa é resultado da interação entre uma pessoa (quem a empina) e um objeto (a pipa)" (INGOLD, 2012, p. 33).

Nessa postura analítica, caminha-se criativamente e improvisadamente "para frente" com processos formativos e não "para trás" em um processo de abdução que se move do objeto acabado até uma intenção na mente do agente. "Os caminhos ou trajetórias através dos quais a prática improvisativa se desenrola não são conexões, nem descrevem relações entre uma coisa e outra [...], mas uma malha de linhas entrelaçadas de crescimento e movimento" (INGOLD, 2012, p. 33). A vida é uma obra em aberto. Ela não busca um fim. Ela é um seguir em frente contínuo.

Seguindo o fluxo do chão afro-brasileiro do Salgueiro, dialogo com os autores acima e reflito sobre como as camisas e fantasias se relacionam fortemente ao corpo e às suas técnicas (BITTER, 2010; MAUSS, 2003), alcançam seus sentidos potentes, quando são percebidas por meio dos movimentos com os/as componentes e revelam-se como participantes ativos na tessitura da vida social (MIZRAHI, 2019).

Nesse sentido, a partir da experiência dançante (PIMENTA, 2017) e das narrativas dos/as componentes, apresentados no momento da entrevista, investiga-se como camisas e fantasias, que marcam a construção estética e política do chão nos ensaios e desfiles da escola, se relacionam com as duas referências que estruturam o desfile das escolas de samba. São elas: a "brincadeira" e o "alegórico". Aqui, dialogo com os conceitos de "samba no pé" e "visual", 
elaborados por Cavalcanti (1994). Para a autora, o "samba" refere-se ao aspecto festivo do desfile, no qual o destaque é a performance coletiva dos componentes, marcada pelo cantar, dançar, brincar o samba enredo. O "visual" refere-se à dimensão plástica do desfile, destacando-se os elementos expressivos como as fantasias, os adereços, as alegorias, e o caráter espetacular. Assim, este artigo tem como foco as camisas e fantasias que constroem o carnaval do Salgueiro.

Precisamente, em termos geográficos, a escola de samba Acadêmicos do Salgueiro, nascida no Morro do Salgueiro, na cidade do Rio de Janeiro, localiza-se na Serra da Carioca, maciço da Tijuca, também chamada de Morro do Mirante. O acesso ao morro dá-se, principalmente, pela Rua General Roca, que se inicia na famosa Praça Sáenz Peña, coração do bairro tijucano, Zona Norte carioca. "Sua população original, formada a partir dos primeiros anos após a abolição da escravatura, congrega muitas famílias negras oriundas do Vale do Paraíba e adjacências e foi, pelo menos até os anos de 1980, forte polo irradiador de tradições culturais de origem africana" (LOPES; SIMAS, 2015, p. 245).

Nos últimos anos, o Salgueiro destaca-se por exibir um "chão" forte, que compete duramente com as coirmãs pelo título de campeã do carnaval carioca. Para os/as componentes, ter um "chão" forte é reunir um grupo de corpos identificados com o pavilhão da escola e com o samba. É viver, experimentar, ensaiar a construção da escola. "No universo das escolas de samba, termo usado para definir a decisiva participação, no desfile carnavalesco, dos integrantes da comunidade de origem de uma escola" (LOPES; SIMAS, 2015, p. 60). A comunidade é formada pela ala, unidades básicas ou células organizacionais das escolas de samba, das baianas, a ala da Velha Guarda, a ala dos compositores, os três casais de mestre-sala e porta-bandeira, a ala dos/as passistas, a ala da bateria, a ala Maculêlê com coreografia, as alas que contam o enredo da escola e, ainda, os/ as componentes das alegorias, a equipe do carro de som, formada por músicos e intérpretes e os diretores de harmonia. O "chão" da escola corresponde à comunidade do Salgueiro em movimento, ou seja, um grande grupo de corpos, que se subdividem nas diversas alas que compõem a agremiação, responsável pelo assentamento da escola e pela performance no dia do desfile. 
A comunidade reúne-se anualmente entre o final de setembro e começo de outubro para recadastramento dos/as integrantes das alas e início dos ensaios. A comunidade é formada de corpos, oriundos de diversos locais: Morro do Salgueiro, Zona Norte, Zona Oeste, Zona Sul, Centro e, ainda, da região metropolitana e de outras cidades mais distantes do município do Rio de Janeiro. Percebe-se, de maneira geral, que grande parte da escola é formada de mulheres negras. Existem ainda homens e pessoas LGBTTQIA+ e LGBTQIAP+ (Lésbicas, Gays, Bissexuais, Transexuais, Queer/Questionando, Intersexo, Assexuais/Arromânticas/Agênero, Pan/Poli e mais). A maioria das/os componentes são negras/os e pardas/os. Os corpos são de todas as idades, de jovens a idosos. Eles variam na forma, na altura, no peso, entre outras dimensões.

Nos últimos anos, esses corpos iniciam os ensaios com a votação na escolha do samba enredo. Nesta fase, restam, aproximadamente, 4 (quatro) sambas enredos em disputa para se tornar o hino oficial da escola para o carnaval do ano seguinte. Os preparativos dessa grande celebração se iniciam no ano anterior ao do desfile. Segundo, Cavalcanti (1999, p. 49), "a confecção de um desfile começa mal terminado o carnaval do ano anterior, com a definição de um novo enredo a ser levado pela escola à avenida". Os ensaios começam no último trimestre do ano e culminam no dia do desfile, no mês de fevereiro ou março, no Sambódromo, local onde ocorrem os desfiles do Grupo Especial e do Grupo de Acesso (Série A) e, ainda, o desfile das escolas mirins. A Avenida Marquês de Sapucaí possui aproximadamente 700 metros de extensão.

Inaugurado em 02 de março de 1984, o Sambódromo é considerado o Templo do Samba. Localizado entre a Praça Onze e o Catumbi, foi construído justamente onde existiu a Pequena África do Rio de Janeiro, concentrando descendentes de africanos [...]. Sua arquitetura é uma criação do renomado Oscar Niemeyer, que só viu a obra concluída conforme o projeto original em 2012, quando foram construídos quatro novos módulos de arquibancadas no espaço anteriormente ocupado por um gigantesco bloco de camarotes (30 ANOS..., 2014).

A construção do Sambódromo "expressou o reconhecimento oficial do potencial turístico, econômico, artístico do desfile na vida da cidade. Essa obra 
trouxe rentabilidade financeira para a festa, mas lhe impôs também condições espaciais muito definidas" (CAVALCANTI, 1999, p. 75). Nesse sentido, por exemplo, a Passarela do Samba é marcada por uma organização espacial, onde os melhores locais são os mais caros. A arquitetura hierarquiza o ato de ver as escolas. Em outras palavras, quem assiste melhor a evolução dos/as componentes da escola na avenida são aqueles/as que podem pagar mais por um ingresso (CAVALCANTI, 1994).

No dia do desfile, os/as componentes passam pisando no chão da avenida do samba com as fantasias e contam corporalmente o enredo da escola. Essas fantasias usadas pelos/as componentes das alas da comunidade são emprestadas pela escola e precisam ser devolvidas posteriormente. Caso o/a componente não devolva a fantasia, ele/a é "automaticamente" cortado/a da ala, sendo proibido/a de desfilar no ano seguinte. O caminho da fantasia é o seguinte: a escola passa ao componente que, depois, repassa à escola. Em seguida, a escola pode vender as fantasias a outras agremiações ou mesmo aproveitá-las.

Os/as componentes ainda têm outros compromissos com a escola, além de devolver a fantasia. Pode-se destacar, primeiramente, que o/a componente deve se inscrever no grupo da comunidade, sendo designado pela direção a compor uma das alas da escola. Ao se inscrever, o componente é obrigado a participar dos ensaios semanais da escola, que atualmente acontecem às quintas-feiras, das $20 \mathrm{~h}$ às $22 \mathrm{~h}$, podendo o/a componente faltar em até três vezes. Caso exceda o número de faltas permitido, ele/a poderá ser cortado/a da escola. Existem ainda outros compromissos importantes com a agremiação, como o ensaio técnico na Avenida Marquês de Sapucaí e a gravação do samba enredo na cidade do samba. Nesses dois eventos, normalmente, os/as componentes ganham uma camisa da escola vermelha e/ou branca. Eles/as devem usar uma peça branca na parte de baixo, compondo o uniforme da escola. Ademais, os/as componentes são convidados a participar dos ensaios específicos com um pequeno grupo de alas, que podem acontecer tanto na quadra quanto na vila olímpica 
da escola, uma do lado da outra, ou na Cidade do Samba, em um dia da semana distinto da quinta-feira, dia oficial de ensaio.

\section{CAMISAS}

Figura 1: Camisas - Ensaio da comunidade no alto do Morro do Salgueiro.

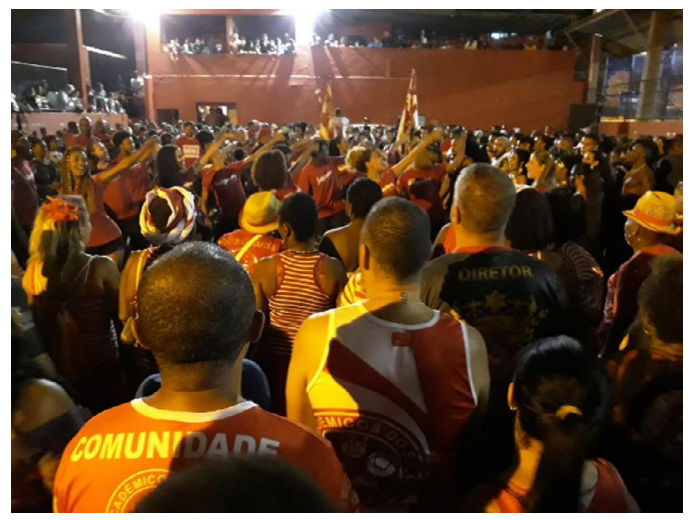

Fonte: Vítor Pimenta, 2017.

Figura 2: Camisas - Ensaio da comunidade no alto do Morro do Salgueiro.

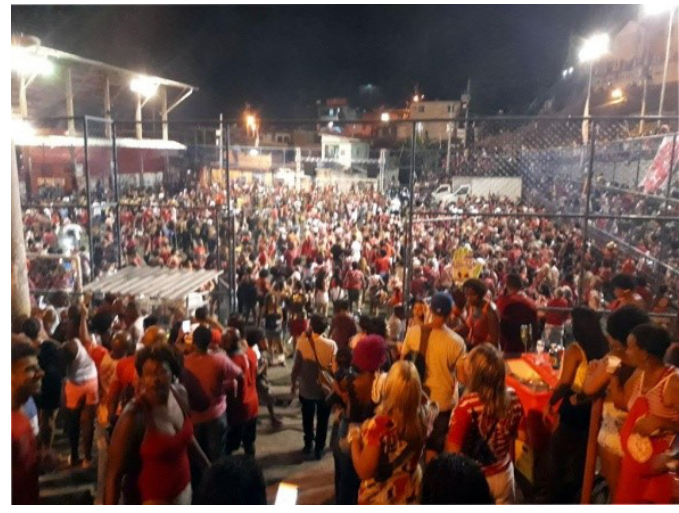

Fonte: Vítor Pimenta, 2018. 
Figura 3: Camisas - Ensaio da comunidade nas ruas Conde do Bonfim e Maxwell.

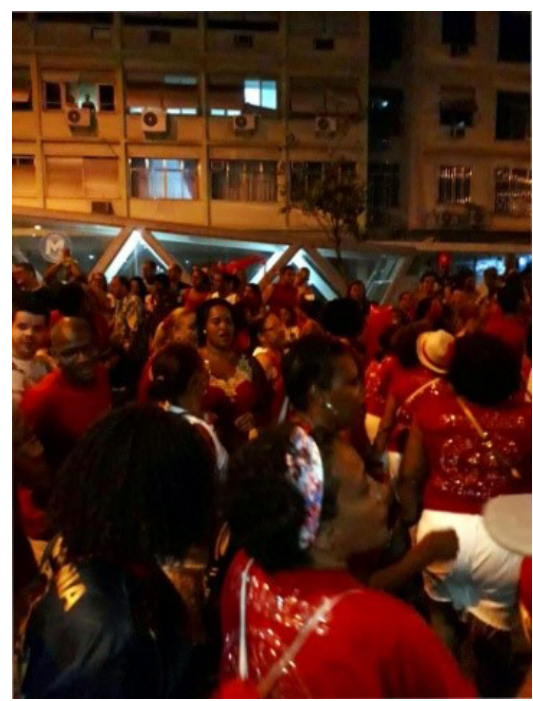

Fonte: Beatriz Freitas, 2018.

Figura 4: Camisas - Ensaio da comunidade nas Ruas Conde de Bonfim e Maxwell.

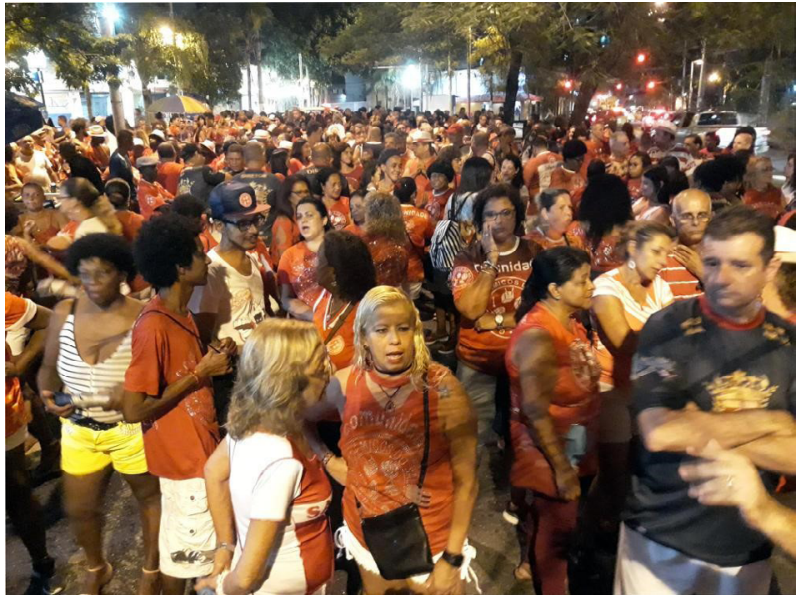

Fonte: Acervo pessoal Vítor Pimenta, 2018.

As camisas vermelhas e brancas do Salgueiro são as vestimentas no dia a dia dos ensaios. Os componentes da agremiação conectam-se às camisas em suas casas e, muitos, cruzam a cidade até chegar à quadra do Salgueiro, ponto de encontro da comunidade, na Rua Silva Teles, no bairro Andaraí. Assim, 
as cores vermelha e branca colorem a cidade no caminhar dos componentes pelas ruas. Ao alcançar a quadra da escola, as camisas se unem para performar o samba enredo da escola e constroem o "chão" vermelho e branco.

Nos ensaios, os corpos juntam-se normalmente às camisas vermelhas e/ou brancas da própria escola. As camisas são normalmente do mesmo modelo e pano - poliéster, algumas podem ter na sua composição $20 \%$ de algodão -, mudando apenas os enredos e, assim, as cores e/ou tonalidades, desenhos e arte. Há ainda a possibilidade do/a componente, por falta de tempo ou outro motivo, não vestir nem uma camisa vermelha e/ou branca ou do Salgueiro. Por exemplo, quando ele/a vem direto do trabalho. Mas grande parte da escola une-se à camisa ou às cores da agremiação nos dias dos ensaios. As camisas são leves e bem menos quente, possibilitando movimentos de braços amplos com um gasto energético menor quando comparadas às fantasias. Entretanto alguns componentes consideram a camisa de poliéster quente quando comparada, por exemplo, a uma camisa de algodão. O material da camisa relaciona-se ao corpo do/a componente, trazendo a sensação de mais ou menos calor e conforto na hora do ensaio, dependendo da malha que o/a toca.

A camisa vermelha e/ou branca torna-se uma obrigação em compromissos como gravações do samba enredo e programas de televisão e, ainda, no ensaio técnico. Entretanto, o diretor de harmonia pode solicitar em um ensaio ou outro que os/as componentes trajem as cores da escola, compondo a parte de baixo com calça, bermuda ou saia na cor branca. Os corpos se ligam de vermelho e/ou branco semanalmente, mudando de vestimenta somente no dia do desfile. Se considerarmos que os ensaios duram entre quatro e cinco meses, ocorrem no mínimo dezesseis ensaios na(s) quadra $(s)^{3}$ e nas ruas, sem contar o ensaio técnico na Sapucaí e outros ensaios/compromissos na Cidade do Samba ou na quadra da escola. Por exemplo, ensaios menores com mais ou menos quatro alas, quando o foco é ensaiar o canto do samba enredo.

Nesses movimentos lúdicos e sensíveis dos corpos que constroem o Salgueiro, percebe-se que o "chão" da escola é assentado com as camisas da escola de vários anos, que se reúnem semanalmente, apresentando uma

\footnotetext{
No carnaval de 2018, houve três ensaios na quadra no alto do Morro do Salgueiro.
} 
estética vermelha e branca. Aqui, dialogo com o trabalho de Lyotard (1988) e Beaudet (2018) e considero os movimentos dos componentes em vermelho e branco como pontos de sensibilidade que fazem os eventos sensíveis. Os eventos (ensaios e desfiles) começam onde se sentem. Uma estética é uma "organização cultural do sensível que faz o evento, que inicia um conhecimento ou um prazer. Uma estética faz os eventos, cada gesto é uma fonte múltipla de conhecimentos de experiências de conhecimento" (BEAUDET, 2018, p. 29). Essas experiências sensíveis que reúnem corpos e camisas celebram o enredo do carnaval presente conjuntamente com os enredos passados, os quais, normalmente, referem-se aos últimos anos, revelando a cada ensaio um mosaico em movimento da história da agremiação.

Em seguida, apresento algumas narrativas dos/as componentes das alas da comunidade referentes aos usos de camisas ao longo dos ensaios semanais.

Gosto [de ir com a camisa do Salgueiro aos ensaios], eu acho que já faz parte, [...] como se fosse uma fantasia. Você colocar a camisa do Salgueiro é como se já estivesse fazendo parte do Salgueiro, é como se fosse o Salgueiro. Como se fosse a fantasia, o Salgueiro. Como se você estivesse fantasiado inteiro. E eu acho muito bonito, as pessoas olham pra você: "Ih, vai pro Salgueiro". [...] É como se fosse uma celebridade... Sempre vermelho, porque é a cor forte da escola (José Rodrigues, 44 anos, negro, dez anos desfilando no Salgueiro, morador do bairro Grajaú).

Essas blusas não saem daqui por nada. Tipo, dá vontade de botar num vidro, tô falando do Salgueiro, porque é do Salgueiro mesmo, porque é do Salgueiro. Colocar a camisa num vidro ali e falar tá aqui. Desfilei esses anos todos, aliás eu tenho acho que pra mais de 500 camisas de ensaio técnico, que eu não dou nenhuma (Orlando Benedito, 53 anos, negro, sete anos desfilando no Salgueiro, morador do bairro Rocha).

Costumo [ir com a camisa do Salgueiro aos ensaios], mas, ultimamente, não tenho ido, porque as camisas que eu tenho é tudo antiga, então eu não costumo colocar. Eu pensei que esse ano ia rolar uma camisa do Salgueiro, não rolou. Aí eu vou de vermelho e branco. Uma rosa no cabelo (Jordênia Lima, "não importa, seje branco, seje morena, seja negra... o que vale é o coração...”, 57 anos, mais de duas décadas desfilando no Salgueiro, moradora do bairro Leme/Babilônia). 
A expectativa. Que eu tenho o maior orgulho de botar... a camisa do Salgueiro. E quanto mais brilho melhor, porque eu sei que as pessoas vão ver que nós somos do Salgueiro. E se não tiver brilho, é uma camisa do Salgueiro que eu tenho o maior orgulho de botar (Marco Aurélio, 61 anos, "sou uma pessoa clara", mais de quatro décadas desfilando no Salgueiro, morador do bairro Piedade).

Tem vez que eu gosto do vermelho e branco... boto um short vermelho e uma blusa branca [...]. Mas não sou de ir toda vez de ensaios com a camisa. Uma que é muito ruim, porque ela não deixa transpirar direito... Esquenta muito [o polyester]. Só isso, mas se fosse [...] duma malha mais legal, até queria. Já minha colega Luzinete, ela anda em casa... Não larga... Qualquer lugar que for, ela bota a camisa e vai (Maria da Penha, 66 anos, negra, 15 anos desfilando no Salgueiro, moradora do bairro Quintino).

A partir das narrativas sobre a relação dos/as componentes e o "uniforme" dos ensaios, percebe-se que a camisa do Salgueiro e as cores vermelha e branca fazem parte da composição corporal dos ensaios semanais. As camisas transformam os/as componentes em parte do Salgueiro, identificados pelos próprios/as e pelos outros como membros da academia do samba e do universo do samba. Como observa Miller (2013), o vestuário tem um papel fundamental na experiência particular do/a componente. "Usar" camisas vermelhas e brancas do Salgueiro, tornam os/as componentes uma versão mais próxima da escola.

As camisas emanam o orgulho, o amor, a devoção à Academia do Samba. Em um ensaio, relacionar-se com uma camisa do Salgueiro ou uma camisa vermelha e branca é preparar-se ritualmente para construir o "chão" da escola. É cobrir-se com seus símbolos, reafirmando a cada ensaio sua união com o pavilhão vermelho e branco. É tingir as ruas da cidade de vermelho e branco, como cantado pelos/as componentes no samba enredo A Divina Comédia do Carnaval (2017): "Gira, baiana, e faz do céu um terreiro / Tinge essa Avenida de vermelho / É nossa missão carnavalizar a vida.” Ao exprimir o samba enredo em movimento, os/as componentes revelam uma estética vermelha e branca, que reverbera uma política afro-brasileira, marcada pelo cantar, dançar, batucar (no caso da ala da bateria) coletivamente. Segundo Ligiéro (2011, p. 168), "o samba-enredo ou samba de 
enredo, conta a história de um herói do passado ou do presente, de divindades cujos mitos fazem parte do legado africano no Brasil ou ancestrais que, africanos ou não, tenham feito de suas vidas exemplos virtuosos para a comunidade do samba”. Para o autor, o samba e suas diversas performances buscam experimentar as novidades por meio de uma forma tipicamente africana.

Nesse pisar afro-brasileiro, marcado pelo cantar-dançar-batucar, produz-se uma coreopolítica: “comobilização da ação e dos sentidos, energizada pela ousadia do iniciar o improvável, no chão sempre movente da história [...], pois o que importa é implementar um movimento que, ao se dar, de fato promova o movimento que importa" (LEPECKI, 2011, p. 55). O movimento que interessa é celebrar a vida conjuntamente, cantando, dançando e batucando o samba enredo, que alcança seu ápice no dia do desfile e, nesse momento, encontra-se com uma fantasia.

\section{FANTASIAS}

\section{Figura 5: Ala 16 - Folia Preguiça (A Divina Comédia do Carnaval - Renato Laje e Márcia Laje).}

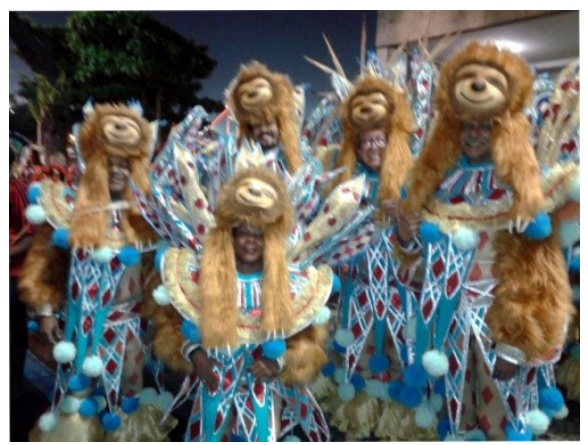

Fonte: Vítor Pimenta, 2017.

O carnaval é a época propícia para exercitar um dos pecados favoritos da massa foliona a preguiça. No caminho para a purificação, Dante se depara com o bloco dos penitentes, aqueles que não têm pressa nenhuma para abandonar a grande festa. No ritmo “é hoje só, amanhã não tem mais", o bloco da Folia 
Preguiçosa segue aproveitando cada momento do breve êxtase carnavalesco (ABRE-ALAS, 2017, p. 278).

Figura 6: Fantasia - Ala 19 e diretores/as de harmonia - A Revolta dos Malês de Luísa Mahin (Senhoras do Ventre do Mundo - Alex de Souza).

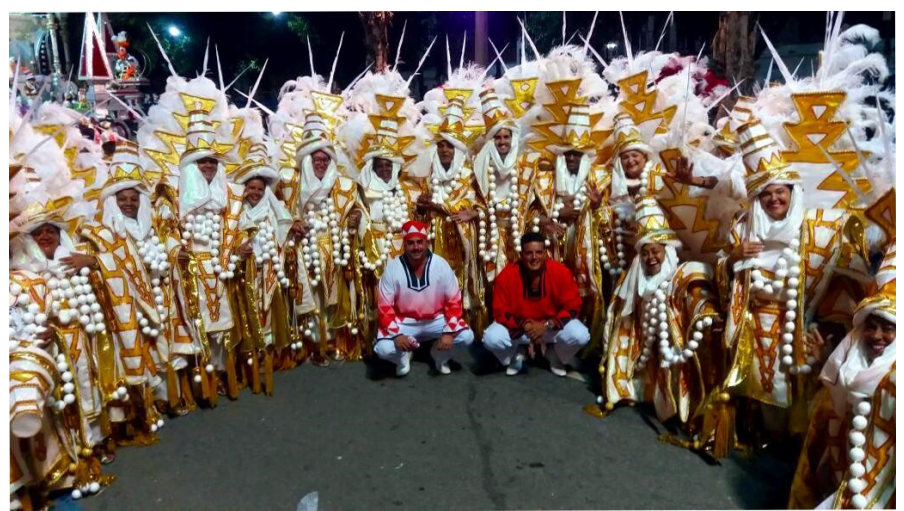

Fonte: Vítor Pimenta, 2018.

Figura 7: Fantasia - Ala 19 e diretores/as de harmonia - A Revolta dos Malês de Luísa Mahin (Senhoras do Ventre do Mundo - Alex de Souza).

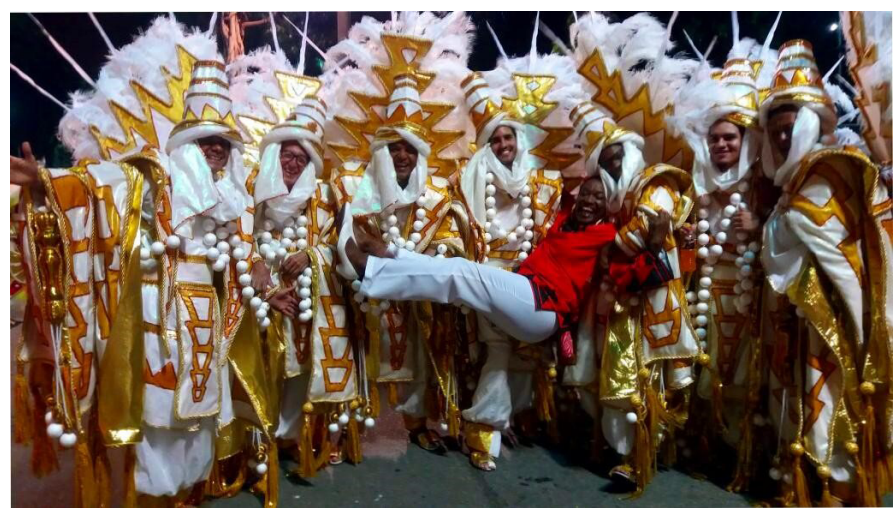

Fonte: Vítor Pimenta, 2018.

A fantasia representa os guerreiros que fizeram parte da mais importante rebelião dos escravos no século XIX: a Revolta do Malês, em janeiro de 1835, na Bahia. O levante foi protagonizado por negros muçulmanos que liam e escreviam em árabe. As formas das fantasias representam essa tradição islâmica. Uma das principais personagens da revolta foi Luísa Mahin, princesa na África, 
que veio como escrava ao Brasil. "'Quituteira' despachava em 'bolinhos', mensagens escritas em árabe para outros rebelados" (ABRE-ALAS, 2018, p. 208).

Neste trabalho, o foco sobre as fantasias está nos corpos responsáveis, fundamentalmente, por desenvolver o enredo da escola na avenida, corpos que formam as alas da comunidade. A abordagem não trata das alas tradicionais da escola, como a ala das baianas e a ala da velha guarda ou, ainda, a ala dos/ as passistas, pois se considera que as fantasias dessas alas se enquadram em outra tipologia, uma vez que cada uma possui um significado distinto dentro da agremiação. As baianas homenageiam, sustentam e sustentaram os valores da civilização africana no Brasil (LUZ, 2017; THEODORO, 2018). Elas são personagens fundamentais na transmissão do saber do samba e espelham a conexão ancestral com as gerações anteriores, assim como a Velha Guarda (RODRIGUES JUNIOR, 2009) reverencia a história dos seus antigos componentes. Passistas, homens e mulheres são responsáveis pela performance gingada do "samba no pé" (TOJI, 2009). As alas da comunidade são a grande massa corporal da escola, onde o chão se faz fortemente. A título de apresentação, no dia do desfile, os/as componentes das alas da comunidade devem estar:

Caracterizados com a mesma fantasia, com os complementos, como meias, sapatos, luvas, chapéus, esplendores iguais. Deve ser um grupo coeso, homogeneamente trajado, com uma dança animada, todos cantando e seguindo em direção ao final da Sapucaí, passando bem pela avenida junto com o restante da escola (GONÇALVES, 2009, p. 228).

A principal função estética das fantasias é retratar visualmente o enredo da escola, através das diversas alas que compõem um desfile. Mais precisamente, as fantasias são compostas de calças, camisas, blusas, vestidos e saias, além de outros elementos. Elementos apoiados na cabeça, ou seja, indumentária usada como chapéu. Elementos apoiados nos ombros - estruturas que se apoiam sobre os ombros caindo sobre o peito e as costas, com um orifício para deixar passar a cabeça do componente. Esplendores ou resplendores, estruturas presas às costas da vestimenta, fixadas por meio de encaixes. Elementos apoiados na cintura, tais como calças, saias, paniers, cinturões. O panier é formado por aros semicirculares, 
presos de cada lado da cintura. Elementos apoiados no pescoço, como colares e similares. Elementos apoiados nos braços e pernas, como pulseiras, braçadeiras e perneiras. Elementos presos aos pés, tais como sapatos e simulações de pés de animais. Elementos presos às mãos, como luvas e alegorias de mão, que podem ser compostas, por exemplo, de bandeiras, estandartes, lanças etc. (CARVALHO, 2010).

No desfile, as fantasias da comunidade são responsáveis por contar o enredo da escola. Nesse sentido, busca-se revelar como os/as componentes da comunidade se relacionam com as fantasias, mas sem abordar a confecção das fantasias no barracão da escola. Em primeiro lugar, de maneira geral, o que elas/es julgam ser mais importante é o conforto e a beleza. As/os componentes avaliam se a fantasia é mais ou menos pesada, mais ou menos confortável, mais ou menos bonita, mais ou menos quente, mais ou menos volumosa, entre outros aspectos. Tocando em suas percepções sobre as fantasias usadas por elas/es no dia do desfile, apresento abaixo algumas narrativas das/os componentes das alas da comunidade. "Foi... o palhaço [fantasia]... porque eu me pintei, me extravasei bastante, e o colorido, eu achei muito lindo ele, o palhaço. Foi marcante mesmo... Bonita... Leve, confortável, bonita [nesta ordem]" (Maria da Penha, 66 anos, negra, 15 anos desfilando no Salgueiro, moradora do bairro Quintino). "[Sobre a fantasia do enredo Fama de Luís XIV] Lembro da peruca... Foi muito legal. Era leve, a parte ruim era a saia porque estava larga. Fiquei segurando a saia, a anágua o desfile inteiro... Estava linda. Maravilhosa” (Alessandra Neto, 27 anos, negra, dez anos desfilando no Salgueiro, moradora do bairro Tijuca).

Não, bonita eu não ligo não, mas assim, leve e confortável, nada que te incomode não... A que eu me senti hiper mega bem foi a de D. João na corte, $[\ldots]$ que foi hors-concours, saí de casa vestido, cheguei elegantérrimo, do Fama (Orlando Benedito, 53 anos, negro, sete anos desfilando no Salgueiro, morador do bairro Rocha).

Se vai ser leve, se vai ser pesada... Isso aí que a gente tem que dar prioridade... porque você tem que evoluir, a fantasia pesada, complicada, o esplendor que te atrapalhe, você não evolui. Esse último, agora, o esplendor machucava muito, aquilo ali, olha, vou te dizer. Eu não fui nas Campeãs, porque eu não tinha condições. Aquilo tava tudo dolorido... 
Mais marcante... eu posso te dizer só a primeira mesmo, que eu desfilei. Foi uma fantasia linda... Chiquérrima! [Xica da Silva]... ali foi uma fantasia que souberam gastar em cima dela, foi uma fantasia linda, maravilhosa (Jordênia Lima, "não importa, seje branco, seje morena, seja negra... o que vale é o coração...", 57 anos, mais de duas décadas desfilando no Salgueiro, moradora do bairro Leme/babilônia).

Não gosto de nada pequenininho. Nada que não apareça. Eu gosto de coisa, assim, muito cheguei! Eu acho que fantasia tem que mostrar. Esse negócio de vir com um paninho... Já chega que quando tiver que sair... na velha guarda vou ter que botar um terno. Pelo amor de Deus. Quero mostrar uma roupa que, pelo menos, o pessoal diga assim: "Nossa que lindo!". [A fantasia do] papagaio... foi linda também... A preguiça estava uma gracinha... Do Joãozinho 30, naquela época, eu desfilei, era "As minas do Rei Salomão". A minha roupa... era tipo um grego! Era muito show! Eu amei aquela roupa (Marco Aurélio, 61 anos, "sou uma pessoa clara", mais de quatro décadas desfilando no Salgueiro, morador do bairro Piedade).

Fantasia bem maneirinha, bem legalzinha, que eu pulei, que foi o bicho, foi do turista. Era a fantasia que eu queria um dia ter desfilado. E eu desfilei. Quando eu vi, é essa que eu quero pular. Quero brincar. Nossa, que delícia, era short a fantasia... Pra mim aquela foi a melhor de todas... Foi muito bom. Foi muito boa... Foi um espetáculo. Uma camisa bem legalzinha. Um desenho de uma máquina fotográfica. Short. Nossa e muito bonitinha. O visual de olhar. Assim, bem legal (Sandra Jesus, 62 anos, negra, mais de 20 anos desfilando no Salgueiro, moradora do bairro Andaraí).

Marcante, bonita foi a de Fama [enredo]. Mais marcante foi Malandro [enredo], não adianta. Aquela capa, aquele chapéu, realmente, quem olhava... E achei engraçado que ela era um terno na frente e atrás era aberta. Ou seja, fresca, não era totalmente fechada... Então eu acho que foi uma fantasia que foi encaixada, foi de acordo com o enredo, foi uma fantasia leve e bonita. Teve a da Portela também, não posso esquecer que desfilei na Portela... foi parecida com essa de Fama, foi uma cartola, capa, terno, calça, e bota, praticamente igual... A primeira coisa que eu penso é se é confortável... Sapato, principalmente. Imagina, você quer sambar com o sapato tá apertado. Ou então o sapato sai do seu pé. Você quer pular, nisso que você pula, você fica com o pé descalço (José Rodrigues, 44 anos, negro, dez anos desfilando no Salgueiro, morador do bairro Grajaú). 
Eu gostei da nêga maluca, do Salgueiro. Gostei da Xica da Silva. [...] Aquele modo de dançar, e tudo, fazendo como se fosse mesmo, o gesto. [...] Ótimo, foi lindo. [...] Todas as minhas fantasias eu gostei de todas, mas essa do Ita [Peguei um Ita no Norte - enredo]. A do malandro! Do malandro também gostei. [...] Adorei. [...] Fica difícil saber a melhor e a mais bonita (Talita Maria, 63 anos, preta, mais de 50 anos desfilando no Salgueiro, moradora do bairro Estácio).

Nas narrativas apresentadas anteriormente, observa-se que os/as componentes preferem uma fantasia leve e bonita. Eles/as desejam estar bonitos/as no dia do desfile, e querem dançar, cantar, isto é, brincar o carnaval. Para que isso aconteça, a fantasia precisa ser leve, possibilitando um movimento harmônico dos corpos com a música, reverberada pelo canto, pela bateria da escola e, ainda, pelo canto do público. O dia do desfile é marcado por essa busca de evolução brincante, unindo corpo e fantasia para contar o enredo da escola.

Em outras palavras, o dia do desfile é o momento de maior esforço corporal do/a componente, quando o corpo se relaciona com a fantasia e com o clima da cidade (INGOLD, 2012). O calor da cidade do Rio de Janeiro no verão desidrata os corpos, fazendo-os suar e molhar as fantasias. Desfilar é enfrentar o desafio de suportar, muitas vezes, um corpo-fantasia pesado e quente sem deixar o corpo esvair-se. É vencer as dores causadas pelo esplendor. Em alguns casos, o/a componente vê seus ombros em "carne viva”, pois o ferro do esplendor "come" sua pele. É resistir à pressão em suas cabeças, causadas por um "chapéu” produzido por material duro e desconfortável. É manter a pisada firme, mesmo que os sapatos estejam apertados. O desafio é brincar, apesar das limitações impostas ao corpo-fantasia. Como se revela nas narrativas a seguir, o que sobressai nessa experiência para os/as componentes é a sensação de transformar-se junto com a fantasia (MILLER, 2013). A proximidade com a fantasia já se torna algo extraordinário.

"É tudo. Aquele brilho, todo mundo lá para ver a gente. Que coisa boa gente. É muito bom isso! Se eu pudesse ficar, ir e voltar várias vezes" (Talita Maria, 63 anos, preta, mais de 50 anos desfilando no Salgueiro, moradora do bairro Estácio). "Dependendo da fantasia, fico até feliz. Como em outras fantasias 
eu penso, meu Deus, passa logo. [O sentimento] é de estar desfilando pela escola que eu gosto, num lugar que eu gosto e tudo que o carnaval representa hoje em dia" (Alessandra Neto, 27 anos, negra, dez anos desfilando no Salgueiro, moradora do bairro Tijuca). "[O que sente quando está fantasiada?] Ah, sambo. Sambo, Maria. Sambo aqui mesmo, fecho as cortinas e tiro... no corredor já tirei e faço uma evolução" (Maria da Penha, 66 anos, negra, 15 anos desfilando no Salgueiro, moradora do bairro Quintino). "Não, muda só, assim, maravilhosa de estar com fantasia na mão, sabe, você tá semanas e semanas ali ensaiando e você pega aquele troféu na tua mão, 'falta pouco pra você desfilar', e quando acaba dá uma tristeza... muito grande” (Jordênia Lima, "não importa, seje branco, seje morena, seja negra... o que vale é o coração..., 57 anos, mais de duas décadas desfilando no Salgueiro, moradora do bairro Leme/Babilônia).

Nossa, é muito bom [estar fantasiado]! A gente passa ali, a gente sente glorioso, grande. O pessoal olha pra você, tanto que eles ficam tão contentes com o que tão vendo, se eles gostarem, eles querem que você dê um pedaço da tua roupa pra eles... Você não pode tirar no meio da Avenida, "toma um chapéu, toma um escudo, toma a capa", e seguir o desfile, não, porque vai perder ponto. Mas assim é muito gostoso, eu saio de casa já esnobe, saio com o nariz lá em cima. Você pega um ônibus ou um metrô, todo mundo te olhando, ah, dá pra se sentir, dá pra tirar uma onda! (Orlando Benedito, 53 anos, negro, 7 anos desfilando no Salgueiro, morador do bairro Rocha).

Sinto muito feliz. Sinto assim como se todo mundo tivesse olhando e eu fico feliz porque as pessoas ficam esperando. Os meus amigos... elas ficam esperando aquele momento de me ver fantasiado... Uma das fantasias que me marcou muito, embora fosse muito calorenta, mas foi muito linda, foi com essa homenagem ao Mestre Louro que a fantasia pesava $7 \mathrm{~kg}$. Só que o peso dela no dia do desfile oficial, quando a bateria desfilou com ela, segundo eles, o peso era muito maior... E eu tenho a maior satisfação de sair vestido de casa! O que não dá pra vestir que eu levo. Mas eu tenho a maior satisfação de botar a roupa (Marco Aurélio, 61 anos, "sou uma pessoa clara", mais de 4 décadas desfilando no Salgueiro, morador do bairro Piedade). 
[O que sente quando está fantasiado?] Eu sou o artista. Tanto é que eu saio de casa fantasiado... Ando no meio da rua. Faço questão de sair de casa fantasiado pra todo mundo me vê [...]. Eu gosto de fantasia quando é fabulosa, maravilhosa, realmente, é a fantasia. É a palavra, é certa... Você se fantasia realmente, é uma fantasia pra você ser aquilo ali por alguns instantes. É o que eu falo pra você, é a emoção e a ilusão. Como diz um samba da Mangueira, o que é Carnaval, "é a doce ilusão, é promessa de vida no meu coração". E é verdade, o carnaval é uma ilusão, uma doce ilusão, que traz uma promessa de você viver aquilo ali, e te dá uma garra pra você continuar o ano em si, nessa energia, entendeu? (José Rodrigues, 44 anos, negro, 10 anos desfilando no Salgueiro, morador do bairro Grajaú).

Nessas narrativas, os/as componentes revelam o sentimento provocado pela fantasia. O prazer, a glória e a felicidade, por exemplo, emanam desta relação dos/as componentes com essa "coisa", aguardada ansiosamente ao longo dos meses, mas que é revelada materialmente apenas poucas semanas antes do dia do desfile. Fantasiar-se é a possibilidade de ser outra personagem. Dessa forma, dialogando com Miller (2013), não há separação entre sujeitos e objetos, as fantasias produzem uma nova versão dos/as componentes, transformando-os/as a cada ano em novas personagens.

O corpo-fantasia precisa "causar" na avenida, sendo lindo, fabuloso, maravilhoso, “elegantérrimo", entre outras expressões que saltam nas narrativas das/os componentes entrevistadas. O corpo-fantasia é feito para ser visto e impressionar aquele/a que o observa. O desfile é o dia da glória do/a componente, quando ele/a é o artista da festa. Entretanto, o/a artista experimenta essa noite de magia, atravessado pela alegoria do corpo-fantasia e pela vontade de brincar o carnaval, sambando.

\section{A BRINCADEIRA E O ALEGÓRICO}

Como se observa, as narrativas expostas apresentam uma tensão entre camisas e fantasias que se revela na relação entre os/as componentes e essas "coisas". A tensão aqui se configura, por um lado, na possibilidade de brincar 
livremente, quando os/as componentes são corpos-camisas nos ensaios e, por outro lado, na luta para conseguir brincar, quando eles/as são corpos-fantasias no dia do desfile. Assim, os ensaios podem ser vistos como momentos nos quais a "brincadeira" é experimentada em sua plenitude. Já o desfile é o tempo, no qual o "alegórico" elaborado pelo carnavalesco se sobrepõe à "brincadeira" da comunidade, uma vez que as fantasias limitam os movimentos dos/as componentes. Quando os corpos estão unidos às fantasias para evoluir na avenida, o destaque é a produção "alegórica" da fantasia com suas formas, tecidos, efeitos visuais e cores, já que, de acordo com as narrativas, as fantasias ligadas aos corpos, em sua maioria, dificultam a evolução do canto, da dança, ou seja, do brincar carnaval no desfile.

Eu acho a fantasia, quem faz a fantasia, não bota a fantasia! Primeira questão é essa. Quem desenha a fantasia, costura a fantasia, não bota a fantasia de jeito nenhum! Nós somos um país tropical, o carnaval é no verão, a criatura me bota uma fantasia toda fechada... Jesus do céu, vou fazer o quê? Máscara e o esplendor pra mim, eu bania de vez esplendor. Porque o negócio é tão ruim, que você movimenta, o negócio sobe, prende tua garganta, você quer falar e não consegue, que dirá cantar... Atrapalha completamente e quando agarra um no outro... Então eu acho que fantasia tinha que ser uma coisa mais leve, tinha que ser uma coisa mais fácil de leitura. Você às vezes não entende (José Rodrigues, 44 anos, negro, dez anos desfilando no Salgueiro, morador do bairro Grajaú).

Porque eu vou te contar é um castigo. Eu me sinto castigada. Porque não é possível se fazer fantasias tão pesadas. E agora chegou ao cúmulo de que são três camadas. A primeira você nem vê. Não precisava... Ou perderam o time, o jeito de fazer fantasia. Que eu não acredito que tenha necessidade dessas coisas que estou desfilando. Está insuportável. Pra mim está em um nível insuportável... Eu achei que nós não merecíamos. A nossa ala é maravilhosa. Tem um pique muito maneiro... uma ala como a nossa ficar apática e tendo que... carregando peso. Isso é um castigo. Alguma coisa, aliás, tem que ser feita [...]. Eu fico... revoltada com essas fantasias. Tá incoerente demais. Esse ano foi demais. Eu chamaria de fantasia incoerente. Sem noção. Nós não ensaiamos o ano inteiro para evoluir (Sandra Jesus, 62 anos, negra, mais de 20 anos desfilando no Salgueiro, moradora do bairro Andaraí). 
As narrativas revelam nitidamente a tensão existente entre a concepção de fantasia daqueles que a desenham e daqueles/as que se ligam à fantasia.

Por um lado, temos o/a carnavalesco/a voltado/a para a dimensão "alegórica", "material", "visual" do carnaval, ou seja, direcionado ao aspecto visual da escola. "Descrever a história, roteirizar, desenhar figurinos, criar cenários, fazer a produção, dirigir o show, ver o trabalho pronto na avenida e assistir à catarse coletiva de quatro mil componentes.” (ABRE-ALAS, 2016, p. 59). O personagem carnavalesco é entendido, há algum tempo, como “aquele que além de conceber, realiza um enredo, tornando-se uma espécie de 'diretor geral' de um espetáculo, ou de 'maestro' de uma 'orquestra' ao coordenar a preparação das várias partes de uma escola para o desfile." (CAVALCANTI, 1994, p. 57). Os carnavalescos e/ou carnavalescas podem trabalhar sozinhos, em dupla ou em comissões. Em alguns casos contam com a parceria de equipes numerosas.

Berço das revoluções estéticas que mudaram para sempre o modo de fazer de carnaval, o Salgueiro se orgulha de ter dado início a essa profissão. Foi do visionário Nélson de Andrade, ex-presidente da escola, a ideia de convidar artistas plásticos - primeiro o casal Dirceu e Marie Louise Nery, em 1959, e, depois, Fernando Pamplona e Arlindo Rodrigues, em 1960 - para se aventurarem na doce delícia de fazer carnaval. Estes professores iniciaram outros carnavalescos - Joãosinho Trinta, Renato Lage, Rosa Magalhães, Maria Augusta Rodrigues e Max Lopes -, que beberam na fonte salgueirense para espalhar a luminosidade vermelha e branca por outras escolas e, eternamente, por outros carnavais (ABRE-ALAS, 2016, p. 59).

Ao longo dos carnavais, a função do carnavalesco cresceu e transformou alguns aspectos dos desfiles das escolas de samba. Atualmente, a atribuição do/a carnavalesco/a/ está intimamente ligada ao processo criativo artístico-visual. No caso específico da escola Acadêmicos do Salgueiro, conforme Natal (2014, p. 48), “o Departamento Cultural começou a exercer também essa função no ano em que o carnavalesco Mauro Quintaes foi o carnavalesco da agremiação”. Apesar dessa parceria na Acadêmicos do Salgueiro, há de se destacar, neste mundo artístico dinâmico, a constituição da individualidade artística desse profissional 
no carnaval carioca (SANTOS, 2009), responsável por dar forma às alegorias, adereços e fantasias.

Por outro lado, encontram-se os/as componentes preocupados com a questão do conforto, da materialidade das fantasias e dos movimentos corporais. As fantasias não podem ter um fim em si mesmas, ou seja, elas não podem ser bonitas e desenhadas para ter volume e movimento se os corpos que as carregam não suportam seu peso e formato. Elas não podem ser pensadas como objetos estáticos. As fantasias devem ser bonitas, mas também confortáveis, permitindo que os/as componentes evoluam vibrantes ao longo do desfile. Essa concepção, revelada pelos/as componentes das alas da comunidade, se alinha à dimensão da "brincadeira”, pois só estando leve e confortável é possível executar os movimentos corporais gingados do samba, conseguir a evolução e a harmonia desejada para a competição do desfile. Esta tensão entre o "alegórico" e a "brincadeira" apresenta duas concepções distintas sobre um desfile de carnaval. A primeira é marcada pelo caráter individualista do carnavalesco. A segunda é fruto da vontade coletiva de brincar o carnaval.

O carnavalesco busca no seu trabalho definir sua individualidade artística constantemente. "Na corda bamba entre a consagração e o fracasso de uma escola, os carnavalescos se enveredam em bibliotecas, na internet ou situações do dia-a-dia na busca de ideias para seus desfiles" (ABRE-ALAS, 2016, p. 59). Dialoga com o mundo social que o cerca, a partir da sua busca por soluções visuais, na tentativa de convencer outros carnavalescos, componentes, jurados, comentaristas e o público em geral, de que o seu trabalho possui uma "marca" individual. Ele busca ser reconhecido publicamente como artista (SANTOS, 2009). Os/as componentes buscam fazer no desfile o que eles/as fazem nos ensaios, isto é, ocupar ruas e avenidas para pensar a vida dançando, cantando, batucando e brincando, produzindo um conhecimento estético e político, a partir dos seus corpos brincantes (PIMENTA, 2009).

Podemos desvendar a denominação "fantasia incoerente", referente às Figuras 6 e 7, usada pela componente como uma fantasia que joga contra a própria escola, uma vez que a escola é avaliada, atualmente, por um corpo de julgadores/as em nove quesitos, conforme Manual do Julgador (LIGA 
INDEPENDENTE DAS ESCOLAS DE SAMBA DO RIO DE JANEIRO, 2018). São eles: Bateria, Samba-Enredo, Harmonia, Evolução, Enredo, Alegorias e Adereços, Fantasias, Comissão de Frente e Mestre-Sala e Porta-Bandeira. Dessa forma, se as fantasias dificultam a brincadeira dos/as componentes, elas, ao invés de colaborarem com a performance da escola, acabam por comprometer a evolução e a harmonia do desfile. Como se apresenta na narrativa a seguir:

Gente! Incoerente. Pra mim, incoerente. Eu acho que de repente está pagando bem caro, pagando o campeonato. Não é nessa ala, mas em outras. A gente não sabe, quem tá lá em cima não vê? Tá vendo. Que estamos perdendo... é claro, nós perdemos no samba... Mas podia tá muito melhor. Essa é a verdade (Sandra Jesus, 62 anos, negra, mais de 20 anos desfilando no Salgueiro, moradora do bairro Andaraí).

Nesse sentido dado pela componente da ala da comunidade, o "alegórico" do carnavalesco é visto como limitador da estética da "brincadeira" das/os componentes, colocando em risco o campeonato da agremiação. Percebe-se então uma tensão interna na própria construção da escola entre o "samba" e o "visual". Segundo Cavalcanti (1994), analisando as escolas do Grupo Especial do Rio de Janeiro na década de 1990, essa tensão foi vital para as transformações das escolas ao longo da história do carnaval, proporcionando potência na competição em desfile.

Ao longo dos carnavais, essa tensão alinha as escolas, mais ou menos próximas de cada um desses polos; interfere na competição carnavalesca pela preferência ideológica dos cidadãos; e serve muitas vezes de suporte para oposições de outra natureza. Assim, por exemplo, a escola de samba Estação Primeira da Mangueira produz de si mesma uma imagem identificada ao "samba" que alude à origem de formação das escolas, e defende, no contexto carnavalesco mais amplo, a ideia de uma "tradição" tão apreciada pelos estudiosos da cultura popular. No outro extremo, escolas como a Mocidade ou a Beija-Flor, e seus simpatizantes, tomam o partido decidido do "moderno" e do gosto pela inovação (CAVALCANTI, 1994, p. 53). 
Nesse movimento competitivo do desfile, o carnaval e as escolas de samba podem ser vistos como bem cultural em um circuito amplo de indústrias culturais (RAPOSO, 2011). As escolas perpassadas pela comercialização e expansão social, a partir de suas histórias particulares, se aproximariam de uma ou outra dimensão desta disputa carnavalesca. Dessa maneira, em um carnaval, a tensão entre "samba" e "visual" manifesta uma interação, "entre diferentes grupos sociais e diferentes gêneros expressivos. Sua evolução traz tradições populares para a era da mídia e do mercado num processo cultural fecundo que percorre e agita anualmente o Rio de Janeiro" (CAVALCANTI, 1999, p. 1). E esta tensão se perpetua intraescola, uma vez que a escola caminha no fio da navalha entre o "alegórico" e a "brincadeira". No interior da escola, coexistem concepções distintas do fazer carnaval, que se chocam frontalmente no dia do desfile, como se percebe nas narrativas dos/as componentes.

\section{PROSPECTIVA}

Neste trabalho, investigou-se a relação dos/as componentes das alas da comunidade do Grêmio Recreativo Escola de Samba Acadêmicos do Salgueiro com os objetos: camisas e fantasias. Ao analisar essas duas "coisas", presentes na construção estética e política do "chão" vermelho e branco, verificou-se a tensão entre o "alegórico" e a "brincadeira". A camisa é a vestimenta "oficial" dos ensaios, quando os corpos podem exercitar livremente os movimentos do samba, pulando e brincando o carnaval. A fantasia é a pele do desfile, quando os componentes se transformam em uma personagem do enredo, fantasiados da cabeça aos pés.

Nos ensaios, ao se unir às camisas do Salgueiro ou camisas vermelhas e/ou brancas, o que se destaca no encontro da comunidade é a "brincadeira", ou seja, o aspecto performático do evento, no qual os movimentos são experimentados de corpo inteiro. Os/as componentes destacam a performance do samba nos ensaios semanais, ficando a dimensão "alegórica" das vestimentas em segundo plano. O vermelho e branco das camisas sublinham uma relação 
de pertencimento dos/as componentes com a agremiação, configurando cada membro em parte visual e performática da escola.

No desfile, ao se reunir às fantasias, a dimensão "alegórica" do carnavalesco toma a cena, destacando-se o aspecto plástico do carnaval. As fantasias concebidas pelos carnavalescos acentuam a dimensão "visual" do espetáculo, dificultando a performance dos/as componentes no desfile. Depois de ensaiar por meses, os/as componentes se veem "castigados" por relacionar-se a uma fantasia que nãos os/as permitem evoluir facilmente na passarela do samba, quando a "brincadeira" é preterida em relação à "estética" do carnavalesco.

Nessa tensão entre a "brincadeira" e o "alegórico", os ensaios configuram-se em momentos, quando é possível observar os corpos em movimento, em evolução plena pelas ruas da cidade, "onde um corpo sente o outro corpo, onde um corpo dança o outro corpo, onde corpos se conectam uns aos outros na experiência dinâmica, vital de conhecer e compreender o mundo a partir de seus corpos dançantes, que brincam de sambar o mundo" (PIMENTA, 2017, p. 20). Já o desfile é o período no qual os corpos são tolhidos pelas fantasias, diminuindo consideravelmente a amplitude dos movimentos corporais, a intensidade do canto, enfim, a energia dos/as componentes na avenida. Por fim, o que os/as componentes esperam, a partir de seus corpos, é que a tensão entre "brincadeira" e "alegórico" não comprometa a harmonia e a evolução do desfile. Eles/as sonham em sambar com fantasias lindas e leves, repetindo na Sapucaí aquilo que fazem semanalmente nos ensaios, isto é, brincar "a todo vapor".

\section{REFERÊNCIAS BIBLIOGRÁFICAS}

1. 30 ANOS de Sambódromo. Liesa News, Rio de Janeiro, n. 13, p. 10, 2014. Disponível em: https://bit.ly/2WSx00O. Acesso em: 11 maio 2020.

2. ABRE-ALAS. G.R.E.S. Paraíso do Tuiuti: carnaval 2017. Rio de Janeiro: Liesa, 2017.

3. ABRE-ALAS. G.R.E.S. União da Ilha do Governador: carnaval 2018. Rio de Janeiro: Liesa, 2018. 
4. ABRE-ALAS. G.R.E.S Unidos de Vila Isabel: carnaval 2016. Rio de Janeiro: Liesa, 2016.

5. BEAUDET, Jean-Michel. Escrever-dançar: definir a Antropologia da Dança? In: CAMARGO, Giselle (org.). Antropologia da Dança IV. Florianópolis: Insular, 2018. p. 25-31.

6. BITTER, Daniel. A bandeira e a máscara: a circulação de objetos rituais nas folias de reis. 2008. Tese (Doutorado em Sociologia e Antropologia) - Universidade Federal do Rio de Janeiro, Rio de Janeiro, 2008.

7. CARVAlHO, Marizilda. Criação e Arte: estrutura das fantasias de escolas de samba. In: COLÓQUIO DE MODA, 4., 2010, São Paulo. Anais [...]. São Paulo: Abepem, 2010.

8. CAVALCANTI, Maria Laura Viveiros de Castro. Carnaval carioca: dos bastidores ao desfile. Rio de Janeiro: Funarte: Editora UFRJ, 1994.

9. CAVALCANTI, Maria Laura Viveiros de Castro. O rito e o tempo: ensaios sobre o carnaval. Rio de Janeiro: Civilização Brasileira, 1999.

10. CLIFFORD, James. Objects and selves: an afterword. In: STOCKING, George (org.). Objects and Others: essays on museums and material culture. Madison: University of Wisconsin Press, 1985. p. 236-246.

11. GONÇALVES, José Reginaldo Santos. Antropologia dos objetos: coleções, museus e patrimônios. Rio de Janeiro: Iphan, 2007.

12. GONÇALVES, Renata de Sá. Continuidade no espetáculo da mudança: o casal de mestre-sala e porta-bandeira. In: CAVALCANTI, Maria Laura Viveiros de Castro; GONÇALVES, Renata de Sá (org.). Carnaval em múltiplos planos. Rio de Janeiro: Aeroplano, 2009. p. 221-252.

13. INGOLD, Tim. Trazendo as coisas de volta à vida: emaranhados criativos num mundo de materiais. Horizontes Antropológicos, Porto Alegre, ano 18, n. 37, p. 25-44, 2012. Disponível em: https://bit.ly/2YV2RR4. Acesso em: 11 maio 2020.

14. LEPECKI, André. Coreopolítica e coreopolícia. Ilha, Florianópolis, v. 13, n. 1, p. 41-60, 2011. Disponível em: https://bit.ly/2YQBxTX. Acesso em: 11 maio 2020.

15. LIGA INDEPENDENTE DAS ESCOLAS DE SAMBA DO RIO DE JANEIRO. Manual do Julgador. Rio de Janeiro: Liesa, 2018. Disponível em: https://bit.ly/35PofbK. Acesso em: 11 maio 2020.

16. LIGIÉRO, Zeca. Corpo a corpo: estudo das performances brasileiras. Rio de Janeiro: Garamond, 2011.

17. LOPES, Nei; SIMAS, Luiz Antonio. Dicionário da história social do samba. Rio de Janeiro: Civilização Brasileira, 2015. 
18. LUZ, Marco Aurélio. Agadá: dinâmica da civilização africano-brasileira. 4. ed. Salvador: EDUFBA, 2017.

19. LYOTARD, Jean-François. Le postmoderne explique aux enfants. Paris: Galilée, 1988.

20. MAUSS, Marcel. Sociologia e Antropologia. São Paulo: Cosac Naify, 2003.

21. MILLER, Daniel. Trecos, troços e coisas: estudos antropológicos sobre a cultura material. Rio de Janeiro: Zahar, 2013.

22. MIZRAHI, Mylene. O funk, a roupa e o corpo: caminhos para uma abordagem antropológica da moda. Cadernos de Arte e Antropologia, Salvador, v. 8, p. 105-121, 2019. Disponível em: https://bit.ly/3fEyAMe. Acesso em: 11 maio 2020.

23. NATAL, Vinícius Ferreira. Cultura e memória na escola de samba Acadêmicos do Salgueiro. 2014. Dissertação (Mestrado em Sociologia e Antropologia) Universidade Federal do Rio de Janeiro, Rio de Janeiro, 2014.

24. PIMENTA, Vítor Gonçalves. Algumas reverberações sobre o chão do Salgueiro. In: CONGRESSO DE ANTROPOLOGÍA EM COLOBIA, 16, 2018, Bogotá. Anais [...]. Bogotá, 2017.

25. RAPOSO, Paulo. Virando o outro em Podence: máscaras da pós-ruralidade. Antropolítica, Niterói, n. 30, p. 131-149, 2011.

26. RODRIGUES JUNIOR, Nilton. O que faz a velha guarda, Velha Guarda? In: CAVALCANTI, Maria Laura Viveiros de Castro; GONÇALVES, Renata de Sá (org.). Carnaval em múltiplos planos. Rio de Janeiro: Aeroplano, 2009, p. 309-339.

27. SANTOS, Nilton Silva dos. Estilo autoral e individualidade artística: os carnavalescos no carnaval carioca. In: CAVALCANTI, Maria Laura Viveiros de Castro; GONÇALVES, Renata de Sá (org.). Carnaval em múltiplos planos. Rio de Janeiro: Aeroplano, 2009. p. 156-172.

28. SENGHOR, Léopold. Sobre a negritude. Diógenes, Brasília, n. 2, p. 73-74, 1982.

29. THEODORO, Helena. Martinho da Vila: reflexos no espelho. Rio de Janeiro: Pallas, 2018.

30. TOJI, Simone. Passistas da Mangueira: o desfile das emoções na festa carnavalesca carioca. In: CAVALCANTI, Maria Laura Viveiros de Castro; GONÇALVES, Renata de Sá (org.). Carnaval em múltiplos planos. Rio de Janeiro: Aeroplano, 2009. p. 221-252. 